\title{
TACl:Fc scavenging B cell activating factor (BAFF) alleviates ovalbumin-induced bronchial asthma in mice
}

\author{
Eun-Yi Moon ${ }^{1,2,3}$ and Sook-Kyung Ryu ${ }^{2}$ \\ ${ }^{1}$ Department of Bioscience and Biotechnology \\ Sejong University \\ Seoul 143-747, Korea \\ ${ }^{2}$ Laboratory of Human Genomics \\ Korea Research Institute of Bioscience and Biotechnology (KRIBB) \\ Daejeon 305-806, Korea \\ ${ }^{3}$ Corresponding author: Tel, 82-2-3408-3768; \\ Fax, 82-2-466-8768; E-mail, eunyimoon@sejong.ac.kr \\ and eunyimoon@yahoo.com
}

\section{Accepted 28 March 2007}

Abbreviations: BAFF, B cell activating factor belonging to TNF- $\alpha$ family; BALF, bronchoalveolar lavage fluid; OVA, ovalbumin; PAS, periodic acid-Schiff; Prx, peroxiredoxin; TACl, transmembrane activator and calcium modulator and cyclophilin ligand interactor

\begin{abstract}
Asthma was induced by the sensitization and challenge with ovalbumin (OVA) in mice. B-cell activating factor (BAFF) plays a role in mature $B$ cell generation and maintenance. Here, we investigated whether, BAFF expression was changed in OVA-induced mice and whether the control of BAFF expression level alleviates the symptom of bronchial asthma. BAFF expression was detected in alveolar-associated cells surrounding bronchi of OVA-induced mouse lung tissues. BAFF protein was also increased in OVA-induced mouse serum. The increased BAFF transcripts was detected in OVA-induced mouse splenocytes. OVA-induced asthma was associated with the increased number of eosinophils in bronchoalveolar lavage fluid (BALF). When TACl:Fc scavenging soluble BAFF was injected to OVA-induced mice, a significant inhibition was detected in the thickness of airway smooth muscle and glycol-containing cellular elements in airway that were visualized by hematoxylin/eosin $Y$ and periodic acid-Schiff staining, respectively. In addition, when mice were treated with TACl:Fc protein, BAFF protein level was decreased in alveolar-associated cells surrounding bronchi of OVA-induced mouse lung tissues compared to control mice. When compared to OVA-induced control, TACl:Fc treatment reduced
\end{abstract}

the percentage of non-lymphoid cells and no changes were detected in lymphoid cell population. Hypodiploid cell formation in BALF was decreased by OVA-challenge but it was recovered by TACl:Fc treatment. Collectively, data suggest that asthmatic symptom could be alleviated by scavenging BAFF and then BAFF could be a novel target for the develpoment of anti-asthmatic agents.

Keywords: asthma; B-cell activating factor; ovalbumin; transmembrane activator and CAML interactor protein

\section{Introduction}

Mature $B$ cell generation and maintenance are regulated by B-cell activating factor (BAFF). BAFF is produced by macrophages or dendritic cells upon stimulation with LPS or IFN- $\gamma$. BAFF belongs to the TNF family. Its biological role is mediated by the specific receptors, B-cell maturation antigen (BCMA), transmembrane activator and calcium modulator and cyclophilin ligand interactor (TACI) and BAFF receptor, BAFF-R (Mak and Yeh, 2002; Mackay et al., 2003). BAFF-deficient mice exhibit an almost complete loss of follicular and marginal-zone B lymphocytes (Schiemann et al., 2001). BAFF is associated with autoimmune disorders and induces rheumatic arthritis in a transgenic mouse model (Mackay et al., 1999; Schneider et al., 1999). These disorders are well-known Th1-mediated inflammatory diseases. In addition, BAFF induces class-switch DNA recombination to produce $\lg$, $\lg A$ and $\lg E$ (Litinskiy et al., 2002), which is in relation to Th2-mediated immune reaction-mediated allergic disorder such as asthma (Rackeman, 1947; Ostergaard, 1985; Corrigan, 2004). Our previous reports show that BAFF protein level was higher in asthma patient, suggesting that BAFF could be a novel diagnostic parameter and a novel therapeutic target to treat asthma (Kang et al., 2006). As the spleen cells were stimulated with Toll-like receptor 4 agonist, LPS, BAFF expression was dependent on reactive oxygen species (ROS) production (Moon et al., 2006).

ROS are produced in mammalian cells in response to the activation of various cell surface receptors. ROS contribute to intracellular signaling processes which in turn regulate various biological activities including host defense (Rhee et al., 2000). 
ROS also play an important role in many physiological processes, including immune responses. Furthermore, when ROS are produced in high quantities, or when antioxidant levels are sufficiently low, they are involved in the pathogenesis of various inflammatory disorders, including asthma and arthritis (Tiku et al., 1999; Henricks and Nijkamp, 2001; Park et al., 2004).

Peroxiredoxins (Prxs) play a role in ROS degradation. ROS production increased in Prxll-deficient mice compared to wild type mice. BAFF expression was increased by ROS treatment and Prxll deletion (Moon et al., 2004, 2006; Han et al., 2005, 2006). Asthma induction with ovalbumin (OVA) resulted in the increase of ROS and BAFF (Lee et al., 2004, 2005, 2006; Moon et al., 2006). Reports show that antioxidants alleviate asthmatic symptom (Lee et al., 2005, 2006). However, little is known about the effect of scavenging BAFF on the treatment of asthma.

In this study, we investigate anti-asthmatic effect by scavenging BAFF with TACI:Fc that is a soluble protein comprised of a human IgG1-Fc fused with the extracellular domain of the mouse TACI receptor (Gross et al., 2001; Roque et al., 2006). OVA-induced mouse asthma model was established and TACI:Fc was administered intraperitoneally. Here, we found that TACl:Fc treatment inhibits BAFF protein level and alleviates asthmatic symptom. Data demonstrate that the control of BAFF by scavenging BAFF protein or by inhibiting BAFF expression was a novel strategy to alleviate asthmatic symptom. This suggests that BAFF is a novel target to develop anti-asthmatic drugs.

\section{Materials and Methods}

\section{Mice}

Mice were maintained in the pathogen-free authorized facility in Korea Research Institute of Bioscience and Biotechnology (KRIBB) where the temperature was at $20-22^{\circ} \mathrm{C}$, and the humidity was kept at $50-60 \%$. The dark/light cycles were $12 \mathrm{~h}$. All animal procedures were conducted in accordance with the guidelines of the institutional Animal Care and Use Committee, KRIBB.

\section{Reagents}

IgG was purchased from Jackson ImmunoResearch Laboratories Inc. (West Grove, PA). Recombinant mouse soluble BAFF, rat monoclonal anti-mouse BAFF antibodies (5A8) and biotinylated rat antimouse BAFF antibodies (1C9) were purchased from ALEXIS Corporation (Lausen, Switzerland). 2',7'Dichlorodihydrofluorescein diacetate (DCF-DA) was from Molecular Probe (Carlsbad, CA). ELISA kit for $\lg E$ and $\lg G$ was purchased from Bethyl Laboratories Inc. (Montgomery, TX). Periodic-Acid Schiff (PAS) staining kit, OVA and aluminum hydroxide were purchased from Sigma-Aldrich (St. Louis, MO). Except where indicated, all other materials are obtained from the Sigma (St. Louis, MO).

\section{Production of TACl:Fc protein}

TACI:Fc (1-86 amino acids) tagged with leader sequence was cloned between Hinlll and Xbal sites of dihydrofolate reductase dhfr-containing pcDNA3 vector. COS-7 cell clone stably expressing TACI:FC was selected by the transfection and the incubation in G418-containing media (clone \#5). Cells were induced by the addition of $200 \mathrm{nM}$ methotrexate (Sigma, St. Louis, MO). TACI:Fc was concentrated by the immunoprecipitation with protein G-excellose (Bioprogen, Daejeon, Korea). TACI:Fc proteins were recovered by the elution with $0.1 \mathrm{M}$ glycin buffer $(\mathrm{pH}$ 2.7). Then, the eluate was neutralized by the addition of $1 \mathrm{M}$ Tris- $\mathrm{HCl}(\mathrm{pH}$ 9.0). TACI:Fc was detected by Far western blot in which TACI:Fc was incubated with BAFF protein followed by the incubation with rabbit anti-BAFF antibodies and goat anti-rabbit IgG-HRP. Protein concentration was measured by Bradford assay (Bio-Rad, Philadelphia, PA).

\section{Bronchial asthma induction with OVA}

Female Balb/C mice (20-25 g, 5-6 wk) were obtained from KRIBB (Daejeon, Korea). Mice were sensitized by intraperitoneal injection of $20 \mu \mathrm{g}$ OVA emulsified in $2 \mathrm{mg}$ aluminum hydroxide in a total volume of 100 $\mu$ PBS on days 0 and 14 . On days 28,29 , and 30 , mice were challenged by ultrasonic nebulization exposure to an aerosol of $1 \%$ (w/v) OVA in PBS for 30 min. Twenty-four hours after the last challenge (day 31 ) the mice were sacrificed, and airway inflammation was characterized by histological examination. To test the effect of TACI:Fc on OVA-induced asthma, mice were intraperitonealy injected for three consecutive days with various doses of 100,200 , $400 \mathrm{mg} / \mathrm{kg}$ TACl:Fc protein, $30 \mathrm{~min}$ prior to OVAchallenge.

\section{Bronchoalveolar lavage (BAL)}

The mice were killed with an overdose of ketamin. BAL fluid (BALF) was collected from each animal via cannulation of the exposed trachea and gentle flushing of the lungs with $0.5 \mathrm{ml}$ of PBS three times (total $1.5 \mathrm{ml}$ ). BALF was used to analyze the number of eosinophils, monocytes, macrophages, lymphocytes and the percentage of hypodiploid cell formation. 


\section{Histological analysis}

Cells in BALF were cyto-spinned on slide glass, stained with Giemsa, and observed under light microscope. Immediately after the collection of BALF, the lung was then inflated with $1 \mathrm{ml}$ of $10 \%$ neutral buffered formalin. After the fixation overnight in $10 \%$ formalin solution, lung tissues were embedded in paraffin. Paraffin-embedded tissues were sectioned $4 \mu \mathrm{m}$ thickness and stained with hematoxylin and eo$\sin \mathrm{Y}$. The bronchoalveolar changes were observed under light microscope.

\section{Immunostaining}

Immunohistochemical studies to detect BAFF protein were performed on formalin-fixed and paraffinembedded lung tissue sections. Briefly, antigen was retrieved with Target Retrival solution (DAKO Cytomation, Denmark). Primary biotin-conjugated mouse monoclonal anti-BAFF antibody (1C9) (ALEXIS, San Diego, CA) and secondary streptavidin-conjugated HRP were used to detect BAFF in lung tissues. The antigen-antibody reaction was visualized using diaminobenzidine as a chromogen, with Mayer's hematoxylin counter staining. The specificity of immunostaining was verified by the use of normal mouse IgG instead of primary antibodies, and negative controls always showed negative stains in the tissues.

\section{Periodic-Acid Schiff (PAS) staining}

PAS staining was performed following the instruction's manual (Sigma). Briefly, tissues were deparaffinized and hydrated to deionized water. Glycolcontaining cellular elements in bronchi were visualized by the incubation in periodic acid solution and Schiff's reagent with Mayer's hematoxylin counter staining. When treated with periodic acid, glycols are oxidized to aldehydes. After reaction with Schiff's reagent (a mixture of pararosaniline and sodium metabisulfite), a pararosaniline adduct is released that stains the glycol-containing cellular elements pink to red. Cellular elements which may be demonstrated with the PAS procedure include glycogen, basement membrane, certain epithelial sulfomucins and sialomucins, neutral mucosubstances.

\section{Cell preparation}

Spleens were dissected from control and OVA-induced mice in RPMI 1640 supplemented with 2\% FCS. Splenocytes were obtained by teasing thus spleen gently with plunger of $3 \mathrm{ml}$ syringe and by sieving through $70 \mu \mathrm{m}$ cell strainer (Falcon, Bedford, MA). Red blood cells were removed by incubating with RBC lysis buffer (Sigma) for $2 \mathrm{~min}$. Spleen cells were washed twice with RPMI 1640 medium. Cell numbers were adjusted to appropriate concentrations.

\section{Flow cytometric analyses}

To analysis hypodiploid cell formation, cells in BALF were stained with propidium iodide described in previous report (Moon et al., 2006). Briefly, cells were fixed in $40 \%$ ethanol on ice for $30 \mathrm{~min}$ and then incubated with propidium iodide $(50 \mu \mathrm{g} / \mathrm{ml})$ and RNase $(25 \mu \mathrm{g} / \mathrm{ml})$ at $37^{\circ} \mathrm{C}$ for $30 \mathrm{~min}$. Then, 10,000 cells were analyzed by CELLQuest ${ }^{\text {TM }}$ software in FACScalibur $^{\mathrm{TM}}$ (Becton Dickinson, San Jose, CA).

\section{RT-PCR}

Spleen cell suspension was prepared by above method. RNA was isolated from cells using TRIZOL (Invitrogen, Carlsbad, CA). cDNA was synthesized from $1 \mu \mathrm{g}$ of total RNA, using oligo $\mathrm{dT}_{18}$ primers and superscript reverse transcriptase in a final volume of $21 \mu \mathrm{l}$ (Bioneer, Daejeon, Korea). For standard PCR, one $\mu$ l of the first strand cDNA product was then used as a template for PCR amplification with Taq DNA polymerase (Bioneer). PCR amplification proceeded as follows: 33 thermocycles of $94^{\circ} \mathrm{C}$ for $30 \mathrm{~s}$, $55^{\circ} \mathrm{C}$ for $30 \mathrm{~s}$, and $72^{\circ} \mathrm{C}$ for $30 \mathrm{~s}$, using oligonucleotides specific for BAFF (forward: GCTTTCCAGGGACCAGAGGAAA; reverse: TTACAGCAGTTTTAGGGCACCAA).

\section{Western blot analysis}

Spleen cells were lysed in ice-cold lysis buffer and Western blot analysis was performed as described previously (Moon et al., 2004). Proteins were separated and visualized with the use of anti-BAFF antibodies (Sigma) and enhanced chemiluminescence (ECL) (Pierce, Rockford, IL).

\section{ELISA for mouse BAFF}

BAFF concentration was measured by ELISA according to following method. $100 \mu$ of anti-BAFF antibodies (5A8) diluted in diluent (1\% BSA in PBS, $\mathrm{pH}$ 7.4) were transferred to an ELISA plate and incubated overnight at room temperature. Plate was washed twice with washing buffer $(0.05 \%$ Tween 20 in PBS, $\mathrm{pH} 7.4)$ and blocked with blocking solution (1\% BSA, $5 \%$ sucrose and $\mathrm{NaN}_{3}$ in PBS) for $1 \mathrm{~h}$. After washing plate twice with washing buffer, mouse serum diluted 5 times was added to antibody-coated ELISA plate. Plate was incubated for $2 \mathrm{~h}$ at room temperature and washed again twice. Biotin-conjugated BAFF antibodies (1C9) were added and incubated for $2 \mathrm{~h}$ at room temperature. After washing plate twice, streptavidin-conjugated HRP (R\&D System, Minneapolis, MN) was added and incubated for 
A

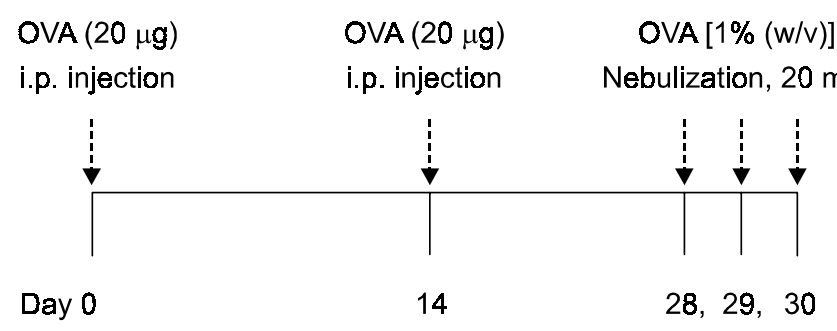

B

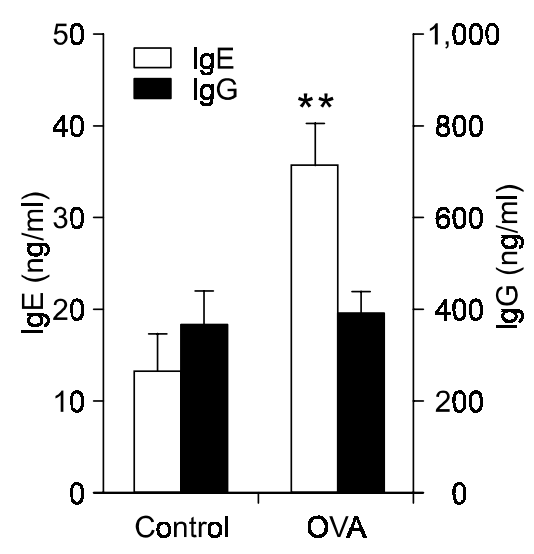

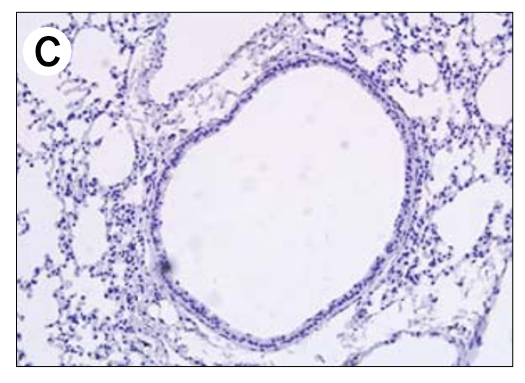

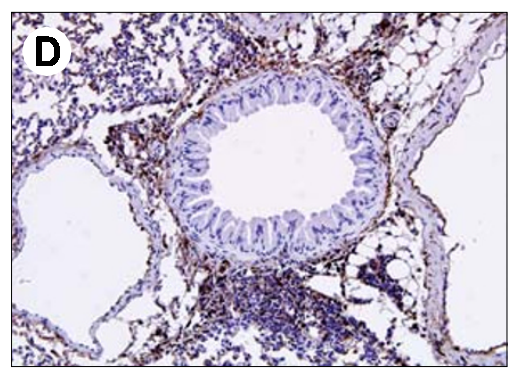

G

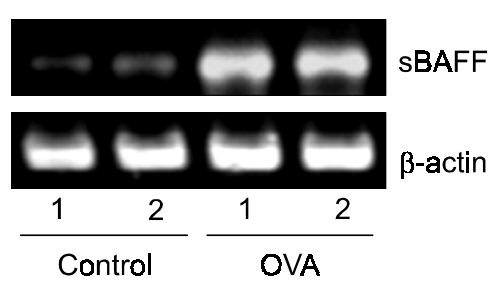

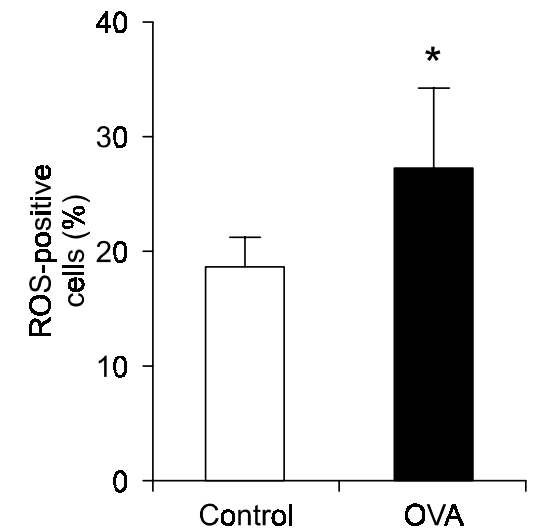

E

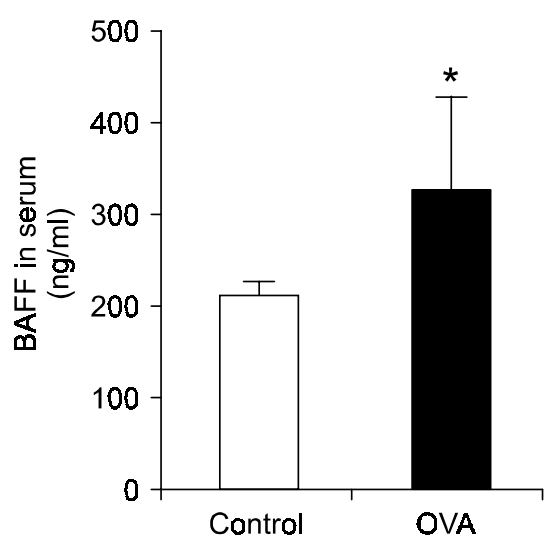

H

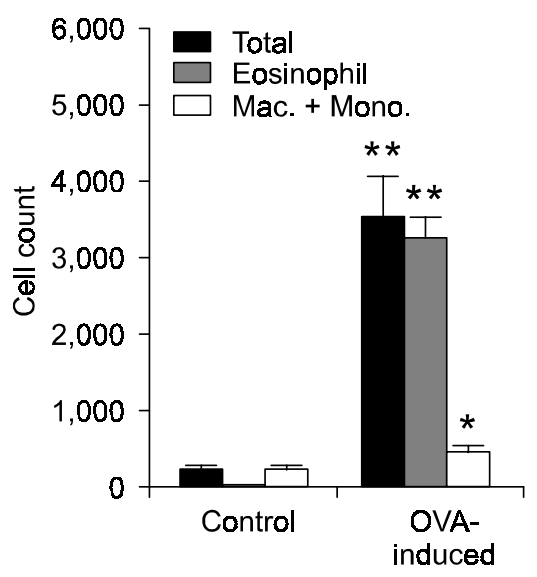

Figure 1. Airway hyperresponsiveness was induced by the sensitization and challenge with OVA. (A) Schedule to induce asthma with OVA. Mice were injected with OVA in aluminum hydroxide at day 0 and day 14. Then, mice were challenged by inhalation with OVA at day 28, 29, and 30. (B) IgE concentration in plasma was measured by ELISA. (C) and (D) Immunohistochemical detection of BAFF in airways from asthma-induced mice with OVA. Lung tissues were incubated with anti-BAFF antibodies and antigen-antibody complexes were visualized with diaminobenzidine. (E) BAFF protein in serum was measured by ELISA. (F) Splenocytes from control and OVA-challenged mice were prepared and RT-PCR was performed for the measurement of BAFF transcripts. (G) ROS production was measured by the incubation with DCF-DA. ROS-positive cells were analyzed by flow cytometry. (H) Bronchoalveolar lavage fluid (BALF) was collected from each animal. Macrophages (Mac.), monocytes (Mono.) and eosinophils were counted by fixing after cytospin and staining with Giemsa. All data were the representative of three experiments. Data in bar graph represent mean \pm SED. ${ }^{*} P<0.05$, ${ }^{* *} P<0.01$; Significantly different from control. 
20 min. Substrate for HRP was 1:1 mixture of color reagent $A\left(\mathrm{H}_{2} \mathrm{O}_{2}\right)$ and color reagent $B$ (tetramethylbenzidine) (R\&D System). After 20 min incubation, $50 \mu$ of $1 \mathrm{M} \mathrm{H}_{2} \mathrm{SO}_{4}$ was added to stop reaction. Absorbance was measured at $450 \mathrm{~nm}$.

\section{Statistical analyses}

Experimental differences were tested for statistical significance using ANOVA and Students' $t$-test. $P$ value of $<0.05$ or 0.01 was considered to be significant.

\section{Results}

\section{BAFF expression detected in OVA-induced mice}

We investigated whether BAFF expression was changed in asthma-induced mice. Mice were
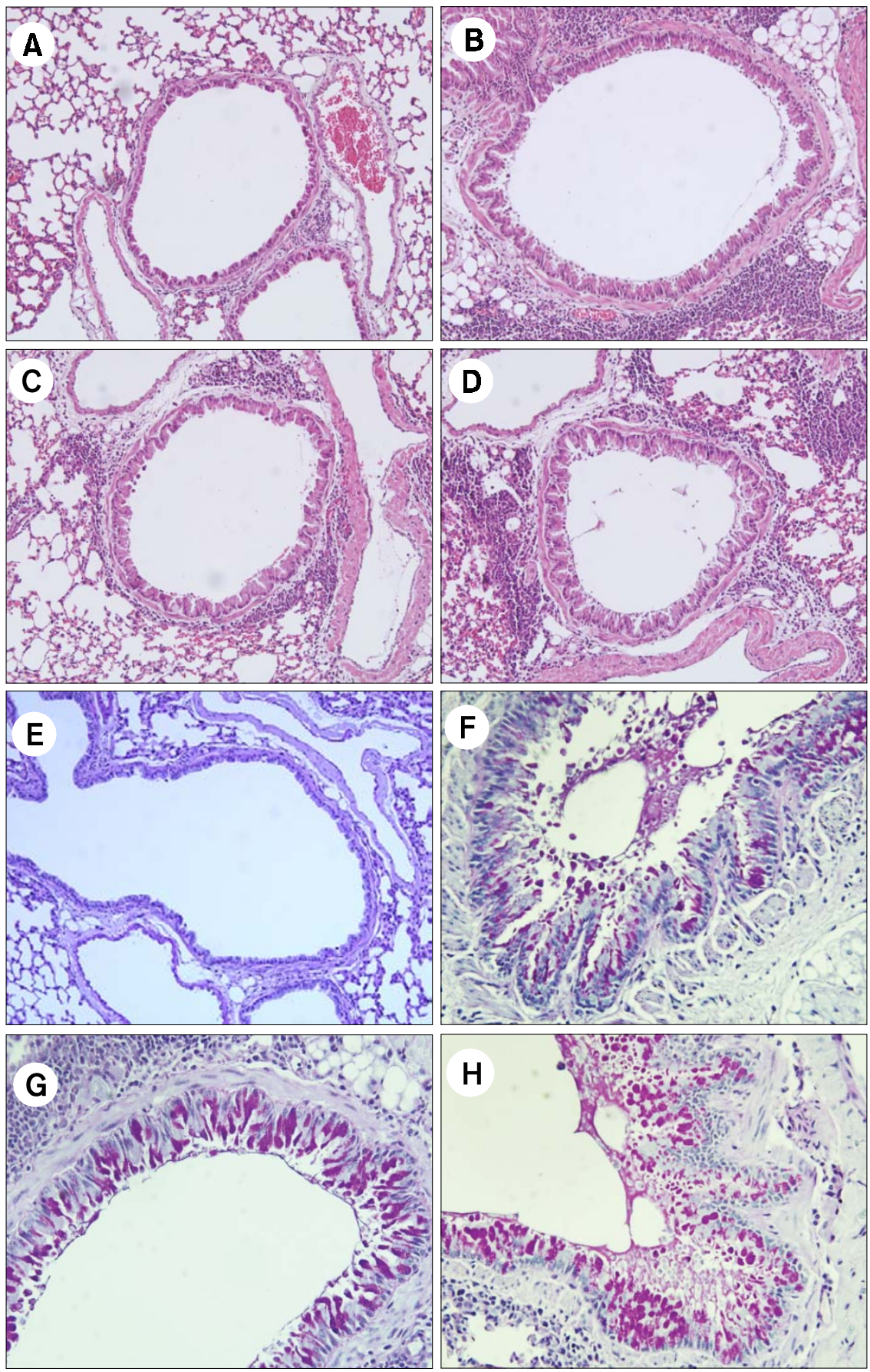

Figure 2. Histopathological observation of TACl:Fc-treated lung tissues of OVAchallenged mice. Lung tissues were fixed, paraffin-embedded, sectioned and stained with hematoxylin/eosin (A, B, C and D). PAS was performed. Glycol-containing cellular elements in bronchi were visualized by the incubation in periodic acid solution and Schiff's reagent with Mayer's hematoxylin counter staining $(E$, $F, G$, and $H)$. Photographs in airway hyper-responsiveness were obtained from control ( $A$ and $E$ ), OVA-induced ( $B$ and F), TACl:Fc (400 mg/kg) treated (C and $\mathrm{G}) \lg \mathrm{G}$ control ( $\mathrm{D}$ and $\mathrm{H}$ ) with a magnification of $\times 200$. All pictures were the representative of 3 experimental tissue samples. 
challenged with OVA twice at the interval of 2 weeks. Then, asthma was induced by the challenge with OVA once a day for three consecutive days (Figure 1A). When compared to control mice, OVA-induced mice showed the increase of $\lg E$ level in serum (Figure 1B) and the thickness of bronchi (Figure 1C and D). OVA-induced lung tissues were immunostained to detect BAFF protein expression. As shown in Figure 1D, BAFF protein was detected in OVA-induced alveolar associated cells surrounding bronchi. BAFF protein level was also increased in OVA-induced mouse serum that was measured by ELISA (Figure 1E). BAFF transcripts were increased in OVA-induced spleen cells (Figure 1F). In accordance with previous reports (van Rijt et al., 2004; Moon et al., 2006), the increased BAFF expression in OVA-induced mice was accompanied by the increased ROS production (Figure 1G) and eosinophil number (Figure $1 \mathrm{H}$ ). It suggests that BAFF could be a novel parameter to detect asthmatic symptom and it also could be a novel target to develop anti-asthmatic agents.

\section{TACI:Fc mediated anti-allergic effect}

To investigate that BAFF is a possible therapeutic target, we used TACI:FC as a scavenger protein to soak up BAFF protein (Gross et al., 2001; Roque et al., 2006; our data not shown). We have cloned TACI:Fc into dihydrofolate (dhfr)-expressing vector and stably expressed TACI:Fc protein in COS-7 cells. TACI:Fc amino acid sequence expressed was based on commercially available protein (ALEXIS). TACI:Fc protein was collected by the immunoprecipitation. The scavenging ability of TACI:Fc protein was determined by the decreased binding of BAFF protein to $B$ cells in the presence of TACl:FC (data not shown). To examine the effect of TACI:FC on OVA-induced asthma, mice were injected with various TACI:Fc doses before challenging mice with OVA for three consecutive days. As shown in Figure $2 A, B, C$, and $D$, the thickness of airway smooth muscle was reduced by the injection of TACI:FC protein. Glycol-containing cellular elements (GCE) in airway were visualized by periodic acid-Schiff (PAS) staining. GCE increased in OVA-challenged asthmatic airway (Larson et al., 2004) was reduced by TACI:Fc treatment compared to control mice (Figure $2 E, F, G$, and $H$ ). It shows that BAFF could be a useful target to develop anti-asthmatic therapeutics.

\section{TACI:Fc reduced BAFF expression}

To find whether scavenging BAFF decreased BAFF protein levels, OVA-sensitized mice were injected with TACl:Fc before challenging with OVA for three consecutive days. When mice were treated with
TACl:Fc protein, BAFF protein level was decreased in alveolar associated cells surrounding bronchi of OVA-induced mouse lung tissues compared to OVA-induced mouse control (Figure $3 \mathrm{~A}, \mathrm{~B}$, and $\mathrm{C}$ ). When treated with normal mouse lgG control, no changes were detected (Figure 3D). As shown in Figure 3E, BAFF protein expression in spleen cells was also reduced by the treatment with various concentrations of TACI:FC and dexamethason (Dex), as a effective anti-asthmatic control agent (Bonacci et al., 2006; Kang et al., 2006). It strengthens above suggestion that BAFF could be a useful target to develop anti-asthmatic therapeutics.

\section{TACl:Fc decreases inflammatory cells and apoptosis, increases lymphocytes}

Bronchoalveolar lavage fluid (BALF) was collected from control, OVA-induced and TACI:Fc-treated mice. Cells were stained with propidium iodide and analyzed by flow cytometry. Based on forward and side scatter characteristics (FSC and SSC), we statistically analyzed lymphoid cells and non-lymphoid cells by gating each cell population. As shown in Figure 4A, OVA increased non-lymphoid cell population including eosinophils. When treated with 100 , $200,400 \mathrm{mg} / \mathrm{kg} \mathrm{TACl}: \mathrm{Fc}$, the percentage of non-lymphoid cell population were significantly decreased. In contact, no changes were detected in the percentage of lymphocytes by OVA-induction and TACI:Fc treatment (Figure 4B). It implicates that BAFF could play a role in the control of non-lymphoid cell population, maybe eosinophils or other types of cells.

To investigate hypodiploid cell formation, cells in BALF were stained with propidium iodide and analyzed by flow cytometer. As shown in Figure 5, hypodiploid cell formation was decreased by OVA-induction. TACI:Fc treatment recovered the percentage of hypodiploid cell formation decreased by OVA-challenge, significantly. This suggests that the scavenging BAFF could be a novel therapeutic way to treat asthma by increasing hypodiploid cell formation.

\section{Discussion}

BAFF is a B cell activating factor which is required for mature $B$ cell generation and maintenance. BAFF is produced by macrophages or dendritic cells upon stimulation with LPS or IFN- $\gamma$ (Mak and Yeh, 2002; Mackay et al., 2003). Previously, we reported that BAFF expression was increased by LPS-stimulated ROS production through nuclear translocation of NF$\kappa \mathrm{B}$ (Moon et al., 2006). BAFF could be a novel parameter to moritor the severity of asthma symptom (Kang et al., 2006). In this study, we investigated whether scavenging BAFF with TACI:Fc in- 

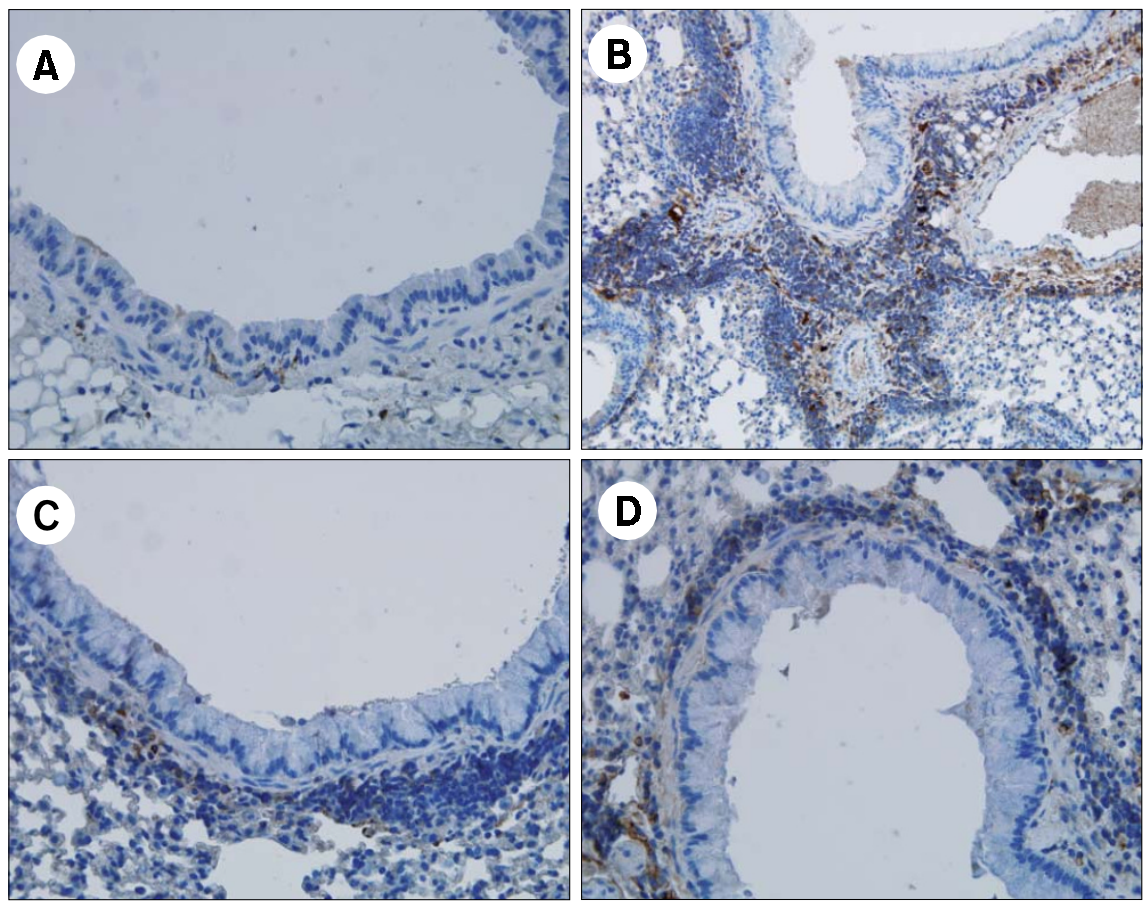

E

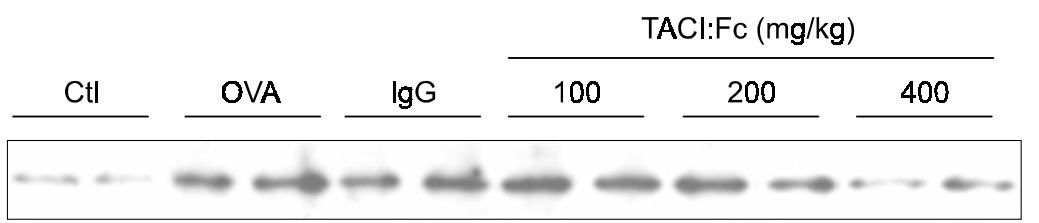

sBAFF

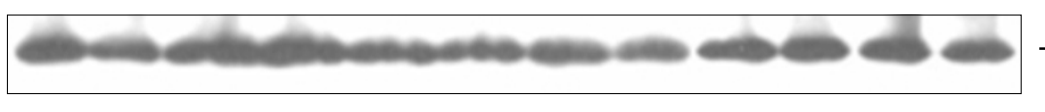

Tubulin

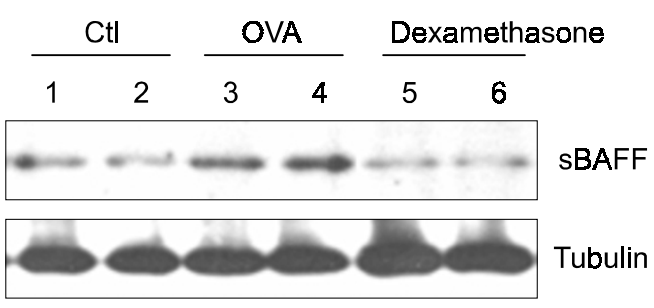

Figure 3. TACl:Fc alleviated asthmatic symptom in OVA-challenged mice. (A) BAFF protein was immunochemically detected in TACl:Fc-treated lung tissues of OVA-challenged mice. BAFF protein was retrieved from paraffinembedded samples and incubated with anti-BAFF antibodies and antigen-antibody complexes. Then, BAFF protein were visualized with diaminobenzidine. (A) Control (B) OVA-induced (C) TACl: Fc (400 mg/kg) treated (D) lgG control photographs were obtained with a magnification of $\times 200$. All pictures were the representative of 3 experimental tissue samples. (E) Western blot analysis was performed to detect BAFF protein changed by the injection of 100 , 200, $400 \mathrm{mg} / \mathrm{kg}$ TACl:Fc (top) or 2 $\mathrm{mg} / \mathrm{kg}$ dexamethasone (bottom). All data were the representative of three experiments. hibits OVA-induced asthmatic symptom. TACI:Fc was effective to treat autoimmune disease, systemic lupus erythematosus (Gross et al., 2001). Here, results show that TACl:Fc was comparably effective to reduce asthmatic symptom. TACI:Fc reduced BAFF expression in splenocytes and asthmatic lung tissue after OVA-challenge, which was detected by western blot analysis and immunohistological staining, respectively. Data suggest that OVA-induced mouse asthma could be applied to develop anti- asthmatic agents targeting BAFF.

TACl:Fc treatment increased non-lymphoid cell population but no changes were detected in lymphoid cell population. According to the report that the number of monocytes and alveolar macrophages does not change significantly (van Rijt et al., 2004), data suggest that eosinophils could be reduced by TACl: Fc treatment. In our experimental condition, OVA increased the number of eosinophils about ten times than inflammatory cells, macrophages and mono- 
A

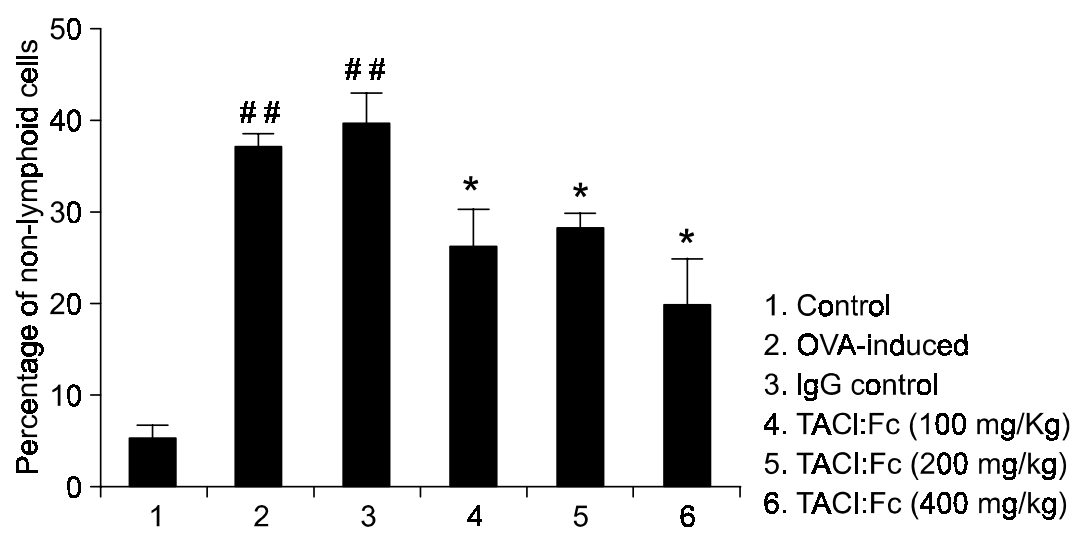

B

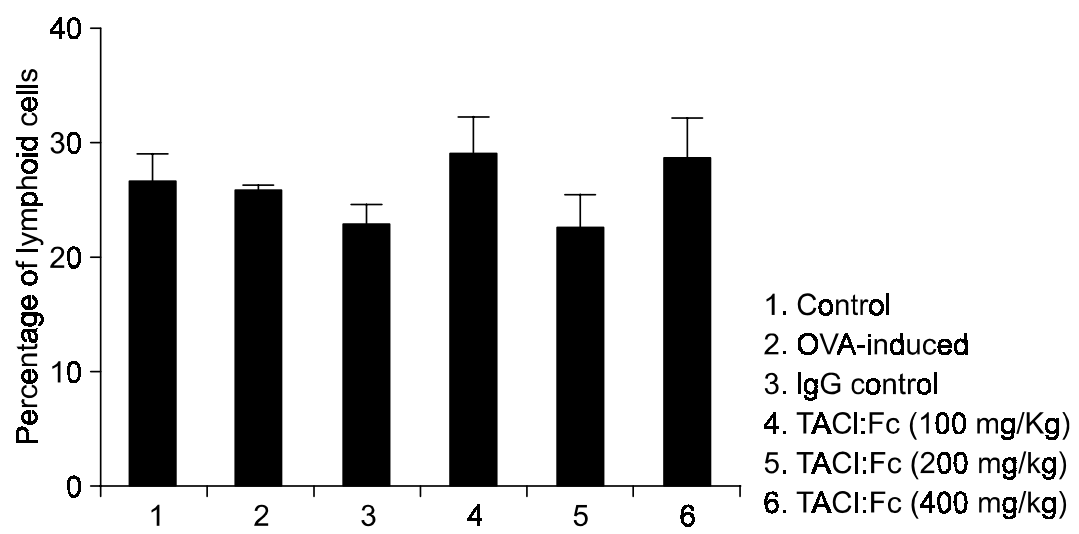

Figure 4. Flow cytometry analysis of cells in BALF. BALF was collected from each animal. Cells were stained with propidium iodide and each cell population was analyzed by flow cytometry. Non-lymphoid (A) and lymphoid cells $(B)$ in BALF were statistically analyzed from FSC-SSC dot plot. All data were the representative of three experiments. Data in bar graph represent mean \pm SED. ${ }^{\#} P<0.01$; Significantly different from control mice. ${ }^{*} P<0.05$; Significantly different from OVA-induced mice.

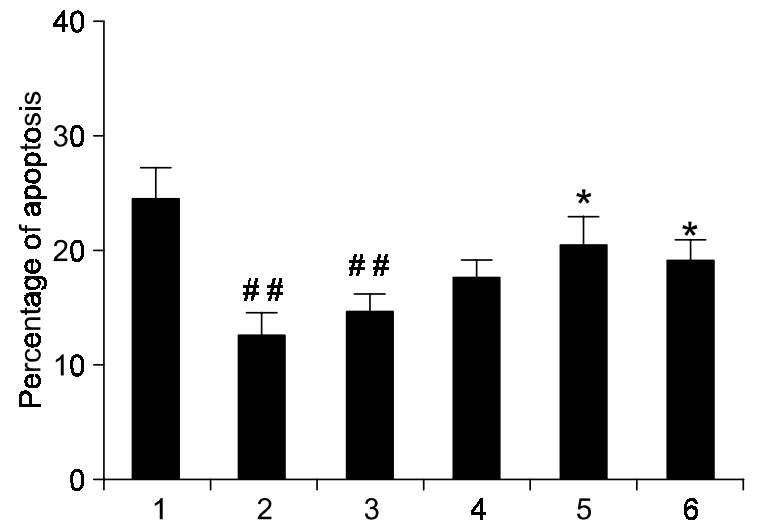

1. Control
2. OVA-induced
3. IgG control
4. TACl:Fc $(100 \mathrm{mg} / \mathrm{Kg})$
5. TACl:Fc $(200 \mathrm{mg} / \mathrm{kg})$
6. TACl:Fc $(400 \mathrm{mg} / \mathrm{kg})$
Figure 5. Aanalysis of hypodiploid cell formation in BAL fluid (BALF). BALF was collected from each animal and cells were stained with propidium iodide. Hypodiploid cell formation was analyzed by flow cytometry. All data were the representative of three experiments. Data in bar graph represent mean \pm SED. ${ }^{\#} P<0.01$; Significantly different from control mice. ${ }^{*} P<0.05$; Significantly different from OVA-induced mice. cytes (Figure $1 \mathrm{H}$ ). Therefore, most of non-lymphoid cell population could be an eosinophil population. It suggests that the changes of non-lymphoid cell count including eosinophils are a critical parameter to determine the effect of anti-asthmatic agents targeting BAFF on OVA-induced asthma.
TACl:Fc treatment increased hypodiploid cell formation decreased by OVA-challenge. Contadictory results were reported in apoptotic cell formation in asthma (Kodama et al., 1998; Cho et al., 2006). In anti-4-1 BB-treated mice to treat allergic asthma, splenocytes exhibited poor proliferation and marked 
apoptosis 7 days after systemic OVA challenge. It suggests that the intervention in the 4-1 BB pathway might provide a potential novel immunotherapeutic approach for treatment of allergic asthma (Cho et al., 2006). The number of apoptotic cells increased concomitantly with the increase in eosinophilic infiltration for 3 days post-OVA-challenge. (Kodama et al., 1998). It suggests that apoptosis induced by OVAchallenge and anti-asthmatic drug treatment could be different from tissue to tissue. This is required to be cleared in the next study.

A few possibities are to explain the effect of TACI:Fc on asthma. OVA-challenge induced BAFF expression (Figure 1), which leads to the reduced hypodiploid cell formation. Scavenging BAFF with TACI:Fc recovered hypodiploid cell formation (Figure 5 ). Recent report showed that B cell depletion recovered from autoimmune disease, systemic lupus erythematosus (Sabahi and Anolik, 2006). Our data also implicate that the increased hypodiploid cell formation may be related to the reduced IgE-producing $B$ cell population. In the case of the treatment of rheumatic arthritis with soluble $\mathrm{TACl}$, the numbers of $B$ cells were not reduced but $B$ cell-dependent disease manifestations were ameliorated (Liu et al., 2004). Although no changes were detected in lymphoid cell population (Figure 4B), there may be a shift in the $T: B$ cell ratio due to the hypodiploid cell formation. The second possibility is that cell cycle arrest leads to apoptotic cell formation (Wang et al., 2005). However, cell cycle arrest on G0/G1 phase is correlated to the reduced apoptotic cell formation in our experimental condition (data not shown). Although little is known about the mechanism of action on these phenomena, data implicate that increased apoptotic cells in BALF are related to the alleviation of asthmatic symptom. The third possible explanation is that hypodiploid cell formation was increased in non-lymphoid cells including eosinophils. Non-lymphoid cell population was increased by OVA-challenge and reduced by TACI:Fc treatment, possibly through hypodiploid cell formation (Figure $4 \mathrm{~A}$ ). Given that $\mathrm{T}$ cell immunoglobulin mucin 3 was involved in macrophage activation in asthma (Chae et al., 2004) and low dose leukotriene receptor antagonist is effective on airway remodeling through anti-inflammation (Muz et al., 2006), TACI:Fc might be effective anti-inflammatory agent against asthma. Each possible mechanism of action will be cleared in the next study. Data suggest that TACI:Fc treatment alleviate asthmatic symptom by the decrease of non-lymphoid cell population increased by OVA-challenge and by the increase of hypodiploid cell formation. These parameters could be useful to find anti-asthmatic candidates targeting BAFF.

In conclusion, although the mechanisms could not be fully defined, data indicates that scavenging BAFF is a new strategy to control asthmatic symptom. Results for the first time suggest that TACI:Fc might play a role in the alleviation of asthmatic symptom.

\section{Acknowledgement}

We thank Drs. Hyung-Kyu Lee, Mi-Young Lee and Hyung-Chin Kim, Korea Research Institute of Bioscience and Biotechnology, Daejeon, Korea, for their experimental assistances on animal maintenance. This work was supported by grants from the Molecular and Cellular BioDiscovery Research Program, Ministry of Science and Technology and National Cancer Control Program, Ministry of Health and Welfare, Korea.

\section{References}

Bonacci JV, Schuliga M, Harris T, Stewart AG. Collagen impairs glucocorticoid actions in airway smooth muscle through integrin signalling. Br J Pharmacol 2006;149:365-73

Chae SC, Song JH, Pounsambath P, Yuan HY, Lee JH, Kim JJ, Lee YC, Chung HT. Molecular variations in Th1-specific cell surface gene Tim-3. Exp Mol Med 2004;36:274-8

Cho YS, Kwon B, Lee TH, Kim TB, Moon KA, La S, Lee J, Lee SD, Oh YM, Moon HB. 4-1 BB stimulation inhibits allergenspecific immunoglobulin $E$ production and airway hyperreactivity but partially suppresses bronchial eosinophilic inflammation in a mouse asthma model. Clin Exp Allergy 2006; 36:377-85

Corrigan C. Mechanisms of intrinsic asthma. Curr Opin Allergy Clin Immunol 2004;4:53-6

Gross JA, Dillon SR, Mudri S, Johnston J, Littau A, Roque R, Rixon M, Schou O, Foley KP, Haugen H, McMillen S, Waggie K, Schreckhise RW, Shoemaker K, Vu T, Moore M, Grossman $\mathrm{A}$, Clegg $\mathrm{CH}$. TACl-Ig neutralizes molecules critical for $\mathrm{B}$ cell development and autoimmune disease. Impaired B cell maturation in mice lacking BLyS. Immunity 2001;15:289-302

Han YH, Kim HS, Kim JM, Kim SK, Yu DY, Moon EY. Inhibitory role of peroxiredoxin II (Prx II) on cellular senescence. FEBS Lett 2005;579:4897-902

Han YH, Kwon JH, Yu DY, Moon EY. Inhibitory effect of peroxiredoxin II (Prx II) on Ras-ERK-NFkappaB pathway in mouse embryonic fibroblast (MEF) senescence. Free Radic Res 2006;40:1182-9

Henricks PA, Nijkamp FP. Reactive oxygen species as mediators in asthma. Pulm Pharmacol Ther 2001;14:409-20

Kang JS, Yoon YD, Ahn JH, Kim SC, Kim KH, Kim HM, Moon EY. B cell-activating factor is a novel diagnosis parameter for asthma. Int Arch Allergy Immunol 2006;141:181-8

Kodama T, Matsuyama T, Miyata S, Nishimura H, Nishioka Y, Kitada O, Sugita M. Kinetics of apoptosis in the lung of mice with allergic airway inflammation. Clin Exp Allergy 1998;28: $1435-43$ 
Larson SD, Plopper CG, Baker G, Tarkington BK, Decile KC, Pinkerton K, Mansoor JK, Hyde DM, Schelegle ES. Proximal airway mucous cells of ovalbumin-sensitized and -challenged Brown Norway rats accumulate the neuropeptide calcitonin gene-related peptide. Am J Physiol Lung Cell Mol Physiol 2004; 287:L286-95

Lee KS, Park HS, Park SJ, Kim SR, Min KH, Jin SM, Park KH, Kim UH, Kim CY, Lee YC. A prodrug of cysteine, L-2oxothiazolidine-4-carboxylic acid, regulates vascular permeability by reducing vascular endothelial growth factor expression in asthma. Mol Pharmacol 2005;68:1281-90

Lee KS, Park HS, Park SJ, Kim SR, Min KH, Jin SM, Li L, Lee YC. An antioxidant modulates expression of receptor activator of NF-kappaB in asthma. Exp Mol Med 2006;38:217-29

Lee YC, Lee KS, Park SJ, Park HS, Lim JS, Park KH, Im MJ, Choi IW, Lee HK, Kim UH. Blockade of airway hyperresponsiveness and inflammation in a murine model of asthma by a prodrug of cysteine, L-2-oxothiazolidine-4-carboxylic acid. Faseb J 2004;18:1917-9

Litinskiy MB, Nardelli B, Hilbert DM, He B, Schaffer A, Casali $P$, Cerutti A. DCs induce CD40-independent immunoglobulin class switching through BLyS and APRIL. Nat Immunol 2002;3: 822-9

Liu W, Szalai A, Zhao L, Liu D, Martin F, Kimberly RP, Zhou T, Carter RH. Control of spontaneous B lymphocyte autoimmunity with adenovirus-encoded soluble TACl. Arthritis Rheum 2004;50:1884-96

Mackay F, Woodcock SA, Lawton P, Ambrose C, Baetscher M, Schneider P, Tschopp J, Browning JL. Mice transgenic for BAFF develop lymphocytic disorders along with autoimmune manifestations. J Exp Med 1999;190:1697-710

Mackay F, Schneider P, Rennert P, Browning J. BAFF AND APRIL: a tutorial on B cell survival. Annu Rev Immunol 2003; 21:231-64

Mak TW, Yeh WC. Signaling for survival and apoptosis in the immune system. Arthritis Res 2002;4 Suppl 3:S243-52

Moon EY, Han YH, Lee DS, Han YM, Yu DY. Reactive oxygen species induced by the deletion of peroxiredoxin II (PrxII) increases the number of thymocytes resulting in the enlargement of Prxll-null thymus. Eur J Immunol 2004;34: 2119-28

Moon EY, Lee JH, Oh SY, Ryu SK, Kim HM, Kwak HS, Yoon WK. Reactive oxygen species augment B-cell-activating factor expression. Free Radic Biol Med 2006;40:2103-11
Muz MH, Deveci F, Bulut Y, Ilhan N, Yekeler H, Turgut T. The effects of low dose leukotriene receptor antagonist therapy on airway remodeling and cysteinyl leukotriene expression in a mouse asthma model. Exp Mol Med 2006;38:109-18

Ostergaard PA. Non-IgE-mediated asthma in children. Acta Paediatr Scand 1985;74:713-9

Park HS, Jung HY, Park EY, Kim J, Lee WJ, Bae YS. Cutting edge: direct interaction of TLR4 with $\mathrm{NAD}(\mathrm{P}) \mathrm{H}$ oxidase 4 isozyme is essential for lipopolysaccharide-induced production of reactive oxygen species and activation of NF-kappa B. J Immunol 2004;173:3589-93

Rackeman FM. A working classification of asthma. Am J Med 1947;33:601-6

Rhee SG, Bae YS, Lee SR, Kwon J. Hydrogen peroxide: a key messenger that modulates protein phosphorylation through cysteine oxidation. Sci STKE 2000;2000:PE1

Roque R, Ponce R, Burleson F, Cabrit M, Broly H, Rogge M. Influenza virus host response of $\mathrm{C} 57 \mathrm{~B} / / 6$ mice treated with TACI-Ig. Immunopharmacol Immunotoxicol 2006;28:13-32

Sabahi R, Anolik JH. B-cell-targeted therapy for systemic lupus erythematosus. Drugs 2006;66:1933-48

Schiemann B, Gommerman JL, Vora K, Cachero TG, ShulgaMorskaya S, Dobles M, Frew E, Scott ML. An essential role for BAFF in the normal development of $B$ cells through a BCMA-independent pathway. Science 2001;293:2111-4

Schneider P, MacKay F, Steiner V, Hofmann K, Bodmer JL, Holler N, Ambrose C, Lawton P, Bixler S, Acha-Orbea H, Valmori D, Romero P, Werner-Favre C, Zubler RH, Browning JL, Tschopp J. BAFF, a novel ligand of the tumor necrosis factor family, stimulates B cell growth. J Exp Med 1999;189:1747-56

Tiku ML, Gupta S, Deshmukh DR. Aggrecan degradation in chondrocytes is mediated by reactive oxygen species and protected by antioxidants. Free Radic Res 1999;30:395-405

van Rijt LS, Kuipers H, Vos N, Hijdra D, Hoogsteden HC, Lambrecht BN. A rapid flow cytometric method for determining the cellular composition of bronchoalveolar lavage fluid cells in mouse models of asthma. J Immunol Methods 2004;288: $111-21$

Wang AG, Moon HB, Lee MR, Hwang CY, Kwon KS, Yu SL, Kim YS, Kim M, Kim JM, Kim SK, Lee TH, Moon EY, Lee DS, Yu DY. Gender-dependent hepatic alterations in H-ras $12 \mathrm{~V}$ transgenic mice. J Hepatol 2005;43:836-44 